\title{
Prevention of Intra-Operative Cerebrospinal Fluid Leaks by Lumbar Cerebrospinal Fluid Drainage during Endoscopic Endonasal Trans- Sphenoidal Surgery for Pituitary Macroadenomas
}

\author{
Bari MS ${ }^{1}$, Akhtar $\mathbf{S}^{2}$, Alam $\mathrm{MS}^{3}$, Rahman $\mathrm{MA}^{4}$, Asifur Rahman $\mathrm{A}^{5}$, Amin $\mathbf{R}^{6}$, Ansari $\mathrm{A}^{7}$, Nath $\mathrm{HD}^{8}$, \\ Chowdhury $\mathrm{D}^{9}$, Hossain $\mathrm{M}^{10}$, Barua $\mathrm{KK}^{11}$
}

Conflict of interest: There is no conflict of interest relevant to this paper to disclose.

Funding Agency: was not funded by any institute or any group.

Contribution of Authors: Principal Investigator and Manuscript preparationData collection-

Scalp block with anaesthesia-

Editorial formatting-

Copyright: @2020bang.BJNS published by BSNS. This article is published under the creative commons CC-BY-NC license. This license permits use distribution (https://creativecommons. orgf/licences/by-nc/4-0/)reproduction in any medium, provided the original work is properly cited and is not used for commercial purposes.

Received: 21.06 .19

Accepted: 14.09.19

\begin{abstract}
:
Aim and Objective: Postoperative cerebrospinal fluid leak is a recognized complication of endoscopic endonasal trans- sphenoidal surgery for pituitary macroadenomas. In this study we assess the utility of prophylactic use of lumbar drain in preventing intra-operative cerebrospinal fluid leakage during endscopic endonasal transsphenoidal surgery for pituitary macroadenoma which will ultimately reduce the rate of persistent post-operative cerebrospinal fluid leakage.
\end{abstract}

Materials and Methods: 34 patients who underwent endscopic endonasal transsphenoidal surgery for pituitary macroadenoma were dividedd into two groups by non-probability convenient sampling technique. In one group of which lumbar subarachnoid drain were given just before induction of anesthesia named LD Group and another group went through conventional method without giving lumbar drain named No LD Group. In all patients of LD Group 20-30 ml of CSF was drawn through lumbar drain before giving dural incision. Valsalva maneuver was used in each group to identify intraoperative CSF leaks at the end of definitive surgery before repairing the sellar floor.Zero degree rigid endoscope was used in all cases. Intraoperative CSF leak was categorized as 'Yes' or 'No' which was decided by surgeon.Lumbar drains were removed within 24 hours of operation in 16 patients of LD Group and in case 1, who developed intraoperative CSF leak, lumbar drain was removed later.

Results: Thirty four patients were eligible for inclusion, of which 17 were assigned to the LD Group and 17 to the no LD Group. There were no statistically significant differences in patient demographics, tumor pathology, or radiology between the two groups. In LD Group intraoperative CSF leak occurred in 1(5.9\%) patient and leak did not occur in 16(94.1\%) patients, in No LD Group intraoperative CSF leak occurred in 14(82.4\%) patients and leak did not occur in 3(17.6\%) patients. Intraoperative CSF drainage significantly reduced the incidence of intraoperative CSF leaks from $82.4 \%$ in the No LD group to $5.9 \%$ in the LD group $(\mathrm{P}<0.001)$. There were no catheter related complications.

Conclusion: Intraoperative CSF drainage significantly reduces the incidence of intraoperative CSF leakage in patients undergoing endoscopic endonasal transsphenoidal surgery for pituitary macroadenomas.

Keywords: Pituitary adenoma, endoscopic endonasal trans-sphenoidal surgery, cerebrospinal fluid (CSF), lumbar drain (LD).

Bang. J Neurosurgery 2020; 10(1): 52-56

1. Dr. Mohammad Shahnawaz Bari, Resident \& Medical Officer, Dept. of Neurosurgery, Bangabandhu Sheikh Mujib Medical University, Dhaka

2. Dr.Shaireen Akhtar, Assistant Professor, Dept. of Biochemistry,Khulna Medical College,Khulna

3. Dr. Md Shamsul Alam, Assistant Professor, Dept. of Neurosurgery, Bangabandhu Sheikh Mujib Medical University,Dhaka

4. Dr. Md Atikur Rahman, Associate Professor, Dept. of Neurosurgery, Bangabandhu Sheikh Mujib Medical University, Shahbag, Dhaka

5. Dr. Asifur Rahman, Associate Professor, Dept. of Neurosurgery, Bangabandhu Sheikh Mujib Medical University, Shahbag, Dhaka

6. Dr. Rezaul Amin, Associate Professor, Dept. of Neurosurgery, Bangabandhu Sheikh Mujib Medical University, Shahbag, Dhaka

7. Dr. Ayub Ansari, Associate Professor, Dept. of Neurosurgery, Bangabandhu Sheikh Mujib Medical University, Shahbag,Dhaka

8. Dr. Haradhon Debnath, Professor, Dept. of Neurosurgery, Bangabandhu Sheikh Mujib Medical University,Shahbag,Dhaka

9. Dr. Dhiman Chowdhury, Professor, Dept. of Neurosurgery, Bangabandhu Sheikh Mujib Medical University, Shahbag,Dhaka

10. Dr. Mohammad Hossain, Professor, Dept. of Neurosurgery, Bangabandhu Sheikh Mujib Medical University, Shahbag,Dhaka

11. Dr. Kanak Kanti Barua, Professor, Dept. of Neurosurgery\&Vice Chancellor of Bangabandhu Sheikh Mujib Medical University, Shahbag, Dhaka

Address of Correspondence: Dr.Mohammad Shahnawaz Bari, Resident \& Medical Officer, Department of Neurosurgery, Bangabandhu Sheikh Mujib Medical University, Shahbag,Dhaka-1000, Mobile no:+8801913518094, Email-baribsmmu@gmail.com 


\section{Introduction:}

Prevalence of pituitary adenoma is $16.7 \%$.Pituitary adenomas have been classified into microadenoma (dimension $<1 \mathrm{~cm}$ ) and macroadenoma (dimension> or $=1 \mathrm{~cm}$ ). Pituitary adenomas can be classified further as functional or non functional, depending on their hormonal activity in vivo. $(1,2)$

Surgery is the first line of treatment for nonfunctioning adenomas. Prolactinoma is the only functional adenoma for which medical treatment may be the primary treatment in certain cases. For other functional (GH or ACTH or FSH or LH or TSH secreting) adenomas treatment options primarily consists of surgery or radiation therapy. (3) Options of surgical approaches for pituitary adenoma are transsphenoidal and transcranial. Pituitary gland is functionally outside the blood-brain barrier. Transsphenoidal approach is an extra arachnoid approach, requires no brain retraction, no external scar aside from where a fat graft is procured to use in sellar floor repair. ${ }^{(4)}$

The diaphragma sella forms the roof of the sella turcica. It covers the pituitary gland, except for a small opening in its center, which transmits the pituitary stalk. Arachnoid matter lies above the diaphragma sellae.An outpouching of the arachnoid protruding through central opening in the diaphragma sella into sella turcica in approximately half of the patients. This outpouching, if opened, represents a potential source of postoperative cerebrospinal fluid leakage. ${ }^{(5)}$ During transsphenoidal surgery for pituitary tumors intraoperative CSF leak due to arachnoid tears commonly complicates the surgery, requiring meticulous dural repair to prevent postoperative CSF rhinorrhea and meningitis. Postoperative CSF leaks occur due to failure to recognize an intraoperative CSF leak or a failure of the primary repair of the sellar floor. ${ }^{(6)}$ In recent years due to development of commercially available neuroendoscopic equipments endoscopic endonasal transsphenoidal pituitary surgery has become truly practical. General interest has grown noticeably because of the minimal invasiveness of this procedure. ${ }^{(7)}$

During endoscopic endonasal transsphenoidal surgery for pituitary tumors the rate of intraoperative CSF leak, by using IT(intra-thecal) fluorescein, was $61 \%$ overall, $44 \%$ for tumors $<2 \mathrm{~cm}$ compared to $72 \%$ for tumors $e^{\wedge} 2 \mathrm{~cm}$ and $35 \%$ for tumors $<1.5 \mathrm{~cm} \mathrm{3/4"}$ compared to $68 \%$ for $\mathrm{e}^{\wedge} 1.5 \% \mathrm{~s} / \mathrm{4}^{\prime \prime} \mathrm{cm} .{ }^{(8)}$ Postoperative cerebrospinal fluid leak is a recognized complication of transsphenoidal surgery which occurred in $6 \%$ of cases. Postoperative CSF leaks were significantly more common when treating nonadenomatous disease $(15.8 \%, P=.047)$ and when intraoperative leakage occurred $(12.7 \%, P=.008)$. A high rate of postoperative CSF leaks were also observed following revision surgery $(14.6 \%)$, probably because of increased incidence of intraoperalive leaks. ${ }^{(9)}$

Cerebrospinal fluid drainage through a lumbar drain during transsphenoidal surgery for pituitary macroadenoma reduces rate of intra-operative CSF leaks by diminishing tension on the arachnoid. Cerebrospinal fluid drainage through lumbar drain during transsphenoidal surgery reduced the rate of intraoperative CSF leakage from $41 \%$ to $5 \%$.Intraoperative CSF drainage also reduced the need for operative repair of sellar floor from $32 \%$ to $5 \%$ and there were no significant catheter related complications. ${ }^{10}$

Materials and methods:

Study Type: Controlled surgical interventional study.

Place of study: This study was carried out in the Department of Neurosurgery, Bangabandhu Sheikh Mujib Medical University, Dhaka, Bangladesh.

Period of study: March 2017-August 2018.

Study population: All consecutive patients underwent endoscopic endonasal trans-sphenoidal surgery in the departments of Neurosurgery, Bangabandhu Sheikh Mujib Medical University, Dhaka; Dhaka Medical College and hospital ; National Institute of Neuroscience and hospital ;Green Life Hospital Limited within the above mentioned period of time.

Sample size: Total sample size was 34 and 17 in each group.

Sampling technique: Non-probability convenient sampling.

Inclusion criteria: Patients with pituitary macroadenoma, evident in preoperative MRI of brain with contrast who undergo endoscopic endonasal trans-sphenoidal surgery.

Exclusion criteria: Patients who underwent previous trans-sphenoidal surgery or extended trans-sphenoidal approach or radiation therapy were. We also excluded patients with pre-existing CSF rhinorrhea and if there was minimal enlargement of sella with a large suprasellar mass on MRI and if histopathological report not consistent with pituitary adenoma.

Study procedure: Subjects were included after primary screening with inclusion and exclusion criteria and 
then divided into two groups by non-probability convenient sampling technique. In one group of which lumbar subarachnoid drain were given just before induction of anesthesia named LD Group and another group went through conventional method without giving lumbar drain named No LD Group.Lumbar subarachnoid drains were given just before induction of anesthesia in either sitting or lateral decubitus position in the lower lumbar region. We did not encounter any difficulties in inserting lumbar drains. In all patients of LD Group 20-30 ml of CSF was drawn through lumbar drain before giving dural incision. Valsalva maneuver was used in each group to identify intraoperative CSF leaks at the end of definitive surgery before repairing the sellar floor.Zero degree rigid endoscope was used in all cases. Intraoperative CSF leak was categorized as 'Yes' or 'No' which was decided by surgeon.Lumbar drains were removed within 24 hours of operation in 16 patients of LD Group and in case 1 case, who developed intraoperative CSF leak it was removed later. Five patients were excluded from the study because histopathology reports were not consistent with pituitary adenoma. One patient was excluded from the study because operating surgeon was confused about intraoperative leak. No patient died during operation.Structured questionnaire was used to collect the necessary information. Informed written consent was taken from each participant or guardian before data collection.

Data processing and analysis: Data were processed and analyzed by using Statistical Package for Social Sciences (SPSS) for Windows version 22.0. Intraoperative CSF leaks were observed in both groups and comparison were done by Chi-square test to see the statistical significance ( $p$-value $<0.05$ ).

Results:

Table-I

Distribution of patients according to age in two groups $(n=34)$

\begin{tabular}{lccc}
\hline Age (years) & $\begin{array}{c}\text { LD Group } \\
(\mathrm{n}=17) \\
\mathrm{n}(\%)\end{array}$ & $\begin{array}{c}\text { No LD Group } \\
(\mathrm{n}=17) \\
\mathrm{n}(\%)\end{array}$ & $\mathrm{p}$-value \\
\hline$\leq 30$ & $7(41.2)$ & $6(35.3)$ & 0.729 \\
$31-40$ & $5(29.4)$ & $9(52.9)$ & 0.163 \\
$>50$ & $5(29.4)$ & $2(11.8)$ & 0.398 \\
Mean \pm SD & $39.64 \pm 13.60$ & $37.52 \pm 13.81$ & 0.655 \\
Range (Min-Max) & $21-61$ & $22-65$ & \\
\hline
\end{tabular}

Unpaired $t$ test was done to measure the level of significance.

Table I shows that majority of the patients $(41.2 \%)$ in LD Group were de 30 years of age and in No LD Group majority $(52.9 \%)$ of the patients were among $31-40$ years of age.
Table-II

Distribution of patients according to gender in two groups $(n=34)$

\begin{tabular}{lccc}
\hline Gender & $\begin{array}{c}\text { LD Group } \\
(\mathrm{n}=17) \\
\mathrm{n}(\%)\end{array}$ & $\begin{array}{c}\text { No LD Group } \\
(\mathrm{n}=17)\end{array}$ & $\mathrm{p}$-value \\
& $12(70.6)$ & $8(47.1)$ & 0.163 \\
\hline Male & $5(29.4)$ & $9(52.9)$ & \\
Female & &
\end{tabular}

Chi-square test was done to measure the level of significance.

Table II shows that male female ratio was 2.4: 1 in LD Group and 1:1.12 in No LD Group.

Table-III

Preoperative mean BMI in two groups $(n=34)$

\begin{tabular}{lccc}
\hline BMI $\left(\mathrm{Kg} / \mathrm{m}^{2}\right)$ & $\begin{array}{c}\text { LD Group } \\
(\mathrm{n}=17)\end{array}$ & $\begin{array}{c}\text { No LD Group } \\
(\mathrm{n}=17)\end{array}$ & $\mathrm{p}$-value \\
\hline Mean \pm SD & $24.94 \pm 3.63$ & $26.30 \pm 4.13$ & 0.317 \\
\hline
\end{tabular}

Unpaired $t$ test was done to measure the level of significance.

Table III shows that mean preoperative BMI in LD Group $24.94 \pm 3.63\left(\mathrm{Kg} / \mathrm{m}^{2}\right)$ and in No LD Group $26.94 \pm 4.13\left(\mathrm{Kg} / \mathrm{m}^{2}\right)$.

Table-V

Distribution of patients according to co-morbidities in two groups $(n=34)$

\begin{tabular}{lccc}
\hline Co-morbidities & $\begin{array}{c}\text { LD Group } \\
(\mathrm{n}=17) \\
\mathrm{n}(\%)\end{array}$ & $\begin{array}{c}\text { No LD Group } \\
(\mathrm{n}=17)\end{array}$ & $\mathrm{p}$-value \\
& $\mathrm{n}(\%)$ & \\
\hline Hypertension & $4(23.5)$ & $6(35.3)$ & 0.452 \\
Diabetes mellitus & $6(35.3)$ & $2(11.8)$ & 0.225 \\
\hline
\end{tabular}

Fisher's exact test was done to measure the level of significance Table V shows that in LD Group 4 (23.5\%) patients and in No LD Group 6 (35.3\%) patients were hypertensive and $6(35.3 \%)$ patients in LD Group and $2(11.8 \%)$ patients in No LD Group were diabetic.

Table-V

$X$-ray skull Lateral View findings of patients in two groups $(n=34)$

\begin{tabular}{lccc}
\hline & $\begin{array}{c}\text { LD Group } \\
(\mathrm{n}=17) \\
\mathrm{n}(\%)\end{array}$ & $\begin{array}{c}\text { No LD Group } \\
(\mathrm{n}=17) \\
\mathrm{n}(\%)\end{array}$ & $\mathrm{p}$-value \\
\hline Anterior clinoid process & & \\
Normal & $17(100.0)$ & $14(87.5)$ & 0.485 \\
Eroded & $0(0.0)$ & $3(12.5)$ & \\
Posterior clinoid process & & \\
Normal & $8(47.1)$ & $6(35.3)$ & 0.728 \\
Eroded & $9(52.9)$ & $11(64.7)$ & \\
\hline
\end{tabular}

Fisher's exact test was done to measure the level of significance 
Table $V$ shows that in LD group anterior clinoid processes were normal in all patients, posterior clinoid processes were eroded in 9(52.9\%) patients, in No LD Group anterior clinoid processes were eroded in $3(12.5 \%)$ patients, posterior clinoid processes were eroded in $11(64.7 \%)$ patients.

Table-VI

Size of the tumor in MRI of brain with contrast in two groups $(n=34)$

\begin{tabular}{lccc}
\hline & $\begin{array}{c}\text { LD Group } \\
(\mathrm{n}=17) \\
\mathrm{n}(\%)\end{array}$ & $\begin{array}{c}\text { No LD Group } \\
(\mathrm{n}=17) \\
\mathrm{n}(\%)\end{array}$ & $\mathrm{p}$-value \\
& & & \\
\hline $\begin{array}{l}\text { Anterior-posterior } \\
\text { diameter (mm) }\end{array}$ & $20.83 \pm 5.29$ & $23.06 \pm 4.97$ & 0.357 \\
$\begin{array}{l}\text { Width (mm) } \\
\begin{array}{l}\text { Cranio-caudal } \\
\text { diameter (mm) }\end{array}\end{array}$ & $25.62 \pm 8.41 \pm$ & $23.87 \pm 5.17$ & 0.193 \\
$\begin{array}{l}\text { Volume of the } \\
\text { tumor }\left(\mathrm{cm}^{3}\right)\end{array}$ & $7.04 \pm 4.55$ & $22.55 \pm 9.52$ & 0.610 \\
\hline
\end{tabular}

Mann-Whitney $U$ test was done to measure the level of significance

Table VI shows that mean volume of tumor in LD group $7.04 \pm 4.55 \mathrm{~cm}^{3}$ and in No LD Group was 7.72 $\pm 3.99 \mathrm{~cm}^{3}$.

Table-VII

Distribution of patients according to intraoperative cerebrospinal fluid leak in two groups $(n=34)$

\begin{tabular}{lccl}
\hline Intraoperative & LD Group & No LD Group & p-value \\
cerebrospinal & $(n=17)$ & $(n=17)$ & \\
Fluid (CSF) leak & $n(\%)$ & $n(\%)$ & \\
\hline Yes & $1(5.9)$ & $14(82.4)$ & $<0.001$ \\
No & $16(94.1)$ & $3(17.6)$ & \\
\hline
\end{tabular}

Chi-square test was done to measure the level of significance

Table VII shows that in LD Group intraoperative CSF leak occurred in $1(5.9 \%)$ patient and leak did not occur in $16(94.1 \%)$ patients. This table also shows that in No LD Group intraoperative CSF leak occurred in $14(82.4 \%)$ patients and leak did not occur in $3(17.6 \%)$ patients.

\section{Dicussion:}

Gondim et al., ${ }^{(11)}$ stated that the goal of transsphenoidal surgery for pituitary adenomas is maximal resection of tumor to decompress the optic apparatus while preserving endocrine function. Postoperative outcomes after surgery for pituitary adenomas are intimately related to the extent of resection because it allows remission of hormone excess in functional tumors, while delaying recurrence in nonfunctional tumors.Currently endoscopic transsphenoidal pituitary surgery has become a preferred alternative option because of its advantages of improved visualization and minimal invasiveness, which allows surgeons to gain access to central skull base lesions. (12)Jakimovski et al.,(8) stated that,during endoscopic endonasal transsphenoidal surgery for pituitary tumors the rate of intraoperative CSF leak, by using IT(intra-thecal) fluorescein, was $61 \%$ overall, $44 \%$ for tumors $<20 \mathrm{~mm}$ compared to $72 \%$ for tumors e" $20 \mathrm{~mm}$. We excluded tumors $>40 \mathrm{~mm}$ in any dimention in our study.

Shiley et al.,(9) showed that postoperative cerebrospinal fluid leak is a recognized complication of transsphenoidal surgery and postoperative CSF leaks were significantly more common when intraoperative leakage occurred (12.7\%, $\mathrm{P}=.008$ ). Insertion of the lumbar drain may be theoretically problematic in obese patients, where localization of the interspinous space may be difficult, especially if fluoroscopy is avoided. In such patients, Jonathan et al. ${ }^{(13)}$ advocate catheter insertion following induction of general anesthesia, which allows administration of an intravenous muscle relaxant that may facilitate easier insertion of the lumbar drain. Despite the fact that most of their patients had elevated BMI values, they did not encounter any difficulties in inserting lumbar drains in overweight patients. Mehta et al.,(10) did not encounter any catheter related complications. We also did not encounter any difficulties in inserting lumbar drains.

Mehta et al., ${ }^{(10)}$ recommended the use of a lumbar subarachnoid catheter to drain CSF intraoperatively during transsphenoidal resection of pituitary macroadenoma. They concluded this from their study of 114 transsphenoidal microscopic surgeries for pituitary macroadenomas performed without intraoperative CSF drainage comparing with findings from 44 miccroscopic surgeries for pituitary macroadenomas in which CSF was drained through a lumbar subarachnoid catheter. They found a dramatic decrease in the intraoperative CSF leak rate from $41 \%$ to less than $5 \%$ in patients who underwent intraoperative drainage of CSF through lumbar subarachnoid catheter. They described that lumbar CSF diversion reduces the turgor of the suprasellar arachnoid that is typically expanded in pituitary adenomas and makes it less susceptible to tearing 
during surgery. In a very recent study, Jonathan et al., ${ }^{(13)}$ performed a randomized controlled trial on 60 pituitary adenoma patients, who were elected for endoscopic endonasal transsphenoidal surgery, of which 30 were assigned to lumbar subarachnoid drainage (LSAD)group and 30 were assigned to no LSAD group.Lumbar drain was successfully inserted in all patients of LSAD group. lintraoperative CSF drainage through lumbar drain during endoscopic endonasal transsphenoidal surgery for pituitary adenoma reduced the incidence of intraoperative CSF leak from $46.7 \%$ in the no LSAD group to $3.3 \%$ in LSAD group.

The results of our study demonstrated that, intraoperative CSF leak was observed in only $1(5.9 \%)$ patient of LD group and 14(82.4\%) patients of No LD Group. So according to our study intraoperative CSF drainage through a lumbar drain, during endoscopic endonasal transsphenoidal surgery for pituitary macroadenomas, reduced the incidence of CSF leaks from $82.4 \%$ to $5.9 \%$, which was statistically significant with a $P$ value of $<0.001$. The results of our nonrandomized controlled trial are consistent with above mentioned other studies and strongly favor the routine use of lumbar subarachnoid catheter to drain CSF intraoperatively during endoscopic endonasal transsphenoidal resection of pituitary macroadenoma.

Conclusion: Intraoperative CSF drainage significantly reduces the incidence of intraoperative CSF leakage in patients undergoing endoscopic endonasal transsphenoidal surgery for pituitary macroadenomas, hence reducing subsequent morbidity associated with this complication.

Acknowledgement: We are grateful to all the teachers,senior and junior colleagues as well as nurses and employees in the Departments of Neurosurgery of Bangabandhu Sheikh Mujib Medical University, Dhaka, Bangladesh, National Institute of Neurosciences, Dhaka, Bangladesh, DMCH, Dhaka, Bangladesh, and Green Life Hospital Limited, Dhaka, Bangladesh who helped me to perform this study.

\section{References:}

1. Ezzat, S., Asa, S.L., Couldwell, W.T., Barr, C.E., Dodge, W.E., Vance, M.L. and McCutcheon, I.E., 2004. The prevalence of pituitary adenomas. Cancer, 101(3), pp.613-619.
2. Hinojosa, A . Q .(ed.), 2012 , 'Multimodal Assessment of Pituitary and Parasellar Lesions $1 / 4$, in Schmidek \& Sweet Operative Neurosurgical Techniques, $6^{\text {th }}$ edn,Elsevier,Philadelphia,pp. 192-202.

3. Greenberg, M. S., 2016c, 'Pituitary Tumors - General Information and Classification $1 / 4$, in Handbook of Neurosurgery, $8^{\text {th }}$ edn, Thieme, Newyork, pp. 718-729.

4. Greenberg, M. S., 2016b,Pituitary Adenomas - Surgical Management, Outcome, and Recurrence Management $1 / 4$, in Handbook of Neurosurgery, $8^{\text {th }}$ edn, Thieme, Newyork, pp. 747-765.

5. Rhoton Jr, A.L., 2002. The sellar region. Neurosurgery, 51(Suppl 1):335-374.

6. Rabadán AT, Hernández D, Ruggeri CS. Pituitary tumors: Our experience in the prevention of postoperative cerebrospinal fluid leaks after transsphenoidal surgery. J Neurooncol 2009;93:127-131.

7. Hinojosa, A. Q .(ed), 2012, 'Endoscopic Endonasal Pituitary and Skull Base Surgery $1 / 4$, in Schmidek \& Sweet Operative Neurosurgical Techniques, $6^{\text {th }}$ edn,Elsevier,Philadelphia,pp. 257-279.

8. Jakimovski, D., Bonci, G., Attia, M., Shao, H., Hofstetter, C., Tsiouris, A.J., Anand, V.K. and Schwartz, T.H., 2014. Incidence and significance of intraoperative cerebrospinal fluid leak in endoscopic pituitary surgery using intrathecal fluorescein. World neurosurgery, 82(3-4), pp.e513-e523.

9. Shiley, S.G., Limonadi, F., Delashaw, J.B., Barnwell, S.L., Andersen, P.E., Hwang, P.H. and Wax, M.K., 2003. Incidence, Etiology, and Management of Cerebrospinal Fluid Leaks Following Transsphenoidal Surgery. The Laryngoscope, 113(8), pp.1283-1288.

10. Mehta, G.U. and Oldfield, E.H., 2012. Prevention of intraoperative cerebrospinal fluid leaks by lumbar cerebrospinal fluid drainage during surgery for pituitary macroadenomas: Clinical article. Journal of neurosurgery, 116(6), pp.1299-1303.

11. Gondim JA, Schops M, de Almeida JP, de Albuquerque LA, Gomes E, Ferraz T, et al. Endoscopic endonasal transsphenoidal surgery: Surgical results of 228 pituitary adenomas treated in a pituitary center. Pituitary 2010;13:68-77.

12. Jankowski, R., Auque, J., Simon, C., Marchal, J.C., Hepner, H. and Wayoff, M., 1992. How I do it: head and neck and plastic surgery: endoscopic pituitary tumor surgery. The Laryngoscope, 102(2), pp.198-202.

13. Jonathan GE, Sarkar S, Singh G, Mani S, Thomas R, Ari George Chacko AG. A randomized controlled trial to determine the role of intraoperative lumbar cerebrospinal fluid drainage in patients undergoing endoscopic transsphenoidal surgery for pituitary adenomas. Neurol India 2018;66:133-8. 